\title{
IIISGUC.ORG
}

"İȘ, GÜC̣" ENDÜSTRi ilLișKiLERI VE INSAN KAYNAKLARI DERGISi

"IS, GUC" INDUSTRIAL RELATIONS AND HUMAN RESOURCES JOURNAL

\section{Türkiye'de Yaşlı Bireylerin Bakım Gereksinimlerine Yönelik Yaşadığı Ortamda Sunulacak Bakım Modelleri}

The Community-Based Care Models For The Need Of Care Of Elderly People In Turkey

\section{Sema OĞLAK}

Yrd. Doç. Dr./Dokuz eylül Üniversitesi

Ekim/October 2011, Cilt/Vol: 13, Say1/Num:4, Page: 115-130 ISSN: 1303-2860, DOI: 10.4026/1303-2860.2011.191.x

Makalenin on-line kopyasına erişmek için:

http://www.isguc.org/?p=article\&id=468\&vol=13\&num=4\&year=2011

To reach the on-line copy of article:

http://www.isguc.org/?p=article\&id=468\&vol=13\&num $=4 \&$ year $=2011$

Makale İçin İletişim/Correspondence to: 
(C) 2000- 2011

"İşGüç" Endüstri İlişkileri ve İnsan Kaynakları Dergisi

"İşGüç" Industrial Relations and Human Resources Journal

Ekim/October 2011, Cilt/Vol: 13, Say1/Num: 4

ISSN: 1303-2860, DOI: 10.4026/1303-2860.2011.191.x

Editör/Editor-in-Chief

Aşkın Keser (Uludă̆ University)

Editör Yardımcıları/Co-Editors

K.Ahmet Sevimli (Uludăg University)

Gözde Yllmaz (Marmara University)

Uygulama/Design

Yusuf Budak (Kocaeli Universtiy)

\author{
Yayin Kurulu / Publishing Committee \\ Dr.Zerrin Firat (Uludă̆ University) \\ Doç.Dr.Aşkın Keser (Kocaeli University) \\ Prof.Dr.Ahmet Selamoğlu (Kocaeli University) \\ Yrd.Doç.Dr.Ahmet Sevimli (Uludağ University) \\ Yrd.Doç.Dr.Abdulkadir Şenkal (Kocaeli University) \\ Yrd.Doç.Dr.Gözde Yilmaz (Kocaeli University) \\ Dr.Memet Zencirkıran (Uludağ University)
}

Uluslararası Danışma Kurulu / International Advisory Board

Prof.Dr.Ronald Burke (York University-Kanada)

Assoc.Prof.Dr.Glenn Dawes (James Cook University-Avustralya)

Prof.Dr.Jan Dul (Erasmus University-Hollanda)

Prof.Dr.Alev Efendioğlu (University of San Francisco-ABD)

Prof.Dr.Adrian Furnham (University College London-İngiltere)

Prof.Dr.Alan Geare (University of Otago- Yeni Zellanda)

Prof.Dr. Ricky Griffin (TAMU-Texas AEM University-ABD)

Assoc. Prof. Dr. Diana Lipinskiene (Kaunos University-Litvanya)

Prof.Dr.George Manning (Northern Kentucky University-ABD)

Prof. Dr. William (L.) Murray (University of San Francisco-ABD)

Prof.Dr.Mustafa Özbilgin (University of East Anglia-UK)

Assoc. Prof. Owen Stanley (James Cook University-Avustralya)

Prof.Dr.Işık Urla Zeytinoğlu (McMaster University-Kanada)

Danışma Kurulu / National Advisory Board

Prof.Dr.Yusuf Alper (Uludağ University)

Prof.Dr.Veysel Bozkurt (Uludağ University)

Prof.Dr.Toker Dereli (Işık University)

Prof.Dr.Nihat Erdoğmuş (Kocaeli University)

Prof.Dr.Ahmet Makal (Ankara University)

Prof.Dr.Ahmet Selamoğlu (Kocaeli University)

Prof.Dr.Nadir Suğur (Anadolu University)

Prof.Dr.Nursel Telman (Maltepe University)

Prof.Dr.Cavide Uyargil (İstanbul University)

Prof.Dr.Engin Yildırım (Sakarya University)

Doç.Dr.Arzu Wasti (Sabancı University)

Dergide yayınlanan yazllardaki görüşler ve bu konudaki sorumluluk yazarlarına aittir.

Yayınlanan eserlerde yer alan tüm içerik kaynak gösterilmeden kullanılamaz.

All the opinions written in articles are under responsibilities of the outhors.

None of the contents published can't be used without being cited. 


\title{
Türkiye'de Yaşlı Bireylerin Bakım Gereksinimlerine Yönelik Yaşadığı Ortamda Sunulacak Bakım Modelleri
}

\author{
The Community-Based Care Models For The Need Of Care Of Elderly \\ People In Turkey
}

\author{
Sema OĞLAK \\ Yrd. Doç. Dr./Dokuz eylül Üniversitesi
}

\begin{abstract}
Özet
Günümüzde yaşl nüfus artışı yalnızca gelişmiş ülkelerin değil gelişmekte ve az gelişmiş ülkelerin de önemli sosyoekonomik ve politik gündeminde yer almaktadır. Yaşlanan nüfusla beraber, sağlık harcamaları ve bakım ihtiyacı da hızla artmaktadır. Nüfusun yaşlanması ve daha uzun yaşama; yalnızca sosyal güvenlik sisteminde değil, aynı zamanda uzun süreli bakım gereksinimi ve yaşam kalitesi ile ilgili sorunları da beraberinde getirmektedir. Bu bağlamda, ortaya çıkacak sorunlara yönelik olarak, maliyeti düşük ve tüm toplumu kapsayacak yeni bakım çözümlerinin bulunmasına ihtiyaç duyulmaktadır. Bakım yükünü̈n artması ve yaşam kalitesi beklentisinin yükselmesi, birçok ülkenin yaşlı bakım politikalarını, kurumsal bakım hizmetlerinden yaşadığı çevrede veya evde bakım hizmetlerine doğru değiştirmelerine ve bütünleşik farklı bakım modellerine yönelmelerine yol açmıştır. Bu çallşmanın amacı, yaşlanma sorunu ile daha önce karşılaşmış ülkelerin maliyetleri azaltan, yaşam kalitesini yükselten ve bakım yükünü azaltan topluma dayalı bakım modeli uygulamalarının ülkemizde de yaygınlaştırılmasına yönelik farkındalı yaratmaktır. Türkiye'nin, gelecekte bireyi toplumundan ayırmayan, memnuniyeti yüksek ve maliyeti düşük bakım modellerine daha fazla ihtiyact olacaktır.
\end{abstract}

Anahtar Kelimeler: Yaşlı, topluma dayalı bakım, yaşam kalitesi, bakım yükü, bakım politikaları.

\begin{abstract}
Currently, the increase of elderly people has been on the important socio-economic and political agenda of not only the developed countries; but of the developing countries, as well. Along with aging population the need of care and health and social care expenditure has rapidly been increasing. Aging of the population and longevity brings along the challenges not only in the social security system, at the same time it brings the problems concerning long-term care and quality of life. In this context, aiming at the problems to arise, both cost-effective and universal new care solutions are needed. With the increase of care burden and the expectation of the quality of life, it is noticed that a lot of countries, in the surrounding where they community or at home, are changing their elderly care policy from the institutional care system services to the community care services, and aiming at the holistic care models. The aim of this study is to raise awareness in our country intending at generalizing the implementation of care models based on the community that increase quality of life, reduce costs and care expenditures of the countries confronted aging problems before. The reason for this is that Turkey will need more care models that will social inclusion an individual, and that will higher level of satisfaction.
\end{abstract}

Key Words: Elderly, community-based care, quality of life, care burden, care policies. 


\section{GíRiş}

Modern yaşamin ve tıp teknolojisinin gelişmesinin en belirgin sonuçlarından biri de, yaşam süresinin uzaması ve yaşlı nüfusun artmasıdır. Yaşlı nüfus artışı gelişmiş ve gelișmekte olan ülkelerde daha fazla olmakla birlikte, son y1llarda daha az gelişmiş ülkelerde de yaşlı nüfusun artışı görülmektedir (Bremner ve diğ., 2010). Dünya nüfusu içinde 65 yaş ve üstündeki bireylerin oranı 2010 'da \% 8 iken, bu oranın 2050 yılında \% 16 'ya ulaşacağ ${ }_{1}$ öngörülmektedir (Population Reference Bureau, 2010; Australian Government Department of Health and Ageing, 2006). Bugün AB nüfusunun yarıs1nın 40 yaş ve üstünde olduğu belirtilmektedir (European Commission Directorate-General for Economic and Financial Affairs, 2009). Nüfus yaşlanmasının en temel göstergelerinin en önemlilerinden biri, 80 yaş ve üstündekilerin nüfus içindeki oranıdır. Gelişmiş ülkelerin birçoğunda, bu oranın çarpıcı bir biçimde yükselmiş olduğu görülmektedir. Sözgelimi, ABD'de son 20 yıldan buyana 85 yaş üstü nüfus 4 kat artmiştır (The Caregiving Project for Older Americans, 2007). İngiltere'de ise, 80 yaş üstündeki bireylerin nüfus içindeki oranının 2008-2013 arasında \% 14 olacağ 1 , buna karş1lık 2006-2031 yılları arasında \% 131 artacağ tahmin edilmektedir (Graham ve diğ., 2010).

Diğer yandan, doğurganlık oranının düşmesiyle birlikte yaşam süresinin uzaması, gelecek 40 yılda yaşlı nüfus sayısındaki artışına, çalışma yaşındaki nüfusun da azalmasına neden olacaktır. Genç nüfusun toplam nüfus içindeki payının azalması ve yaşlı nüfusun toplam nüfus içindeki payının artmasının bir sonucu olarak da yaşlı bağımlılık orani* yükselecektir (Bremner ve diğ., 2010). Dünya Nüfus Verileri (2010)'ne göre, gelişmiş ülkelerde bugün çalışma yaşındaki bir kişi 65 yaş üstündeki 4 kişiyi desteklerken, 2050 'de bu oran 2'ye inecektir. Daha az gelişmiş ülkelerde ise $11^{\prime}$ den 4 'e ineceği öngörülmektedir. Başka bir ifadeyle, daha az gelişmiş ülkelerde yaşlanma hızının daha fazla olacağ1 tahmin edilmektedir (Ringheim, 2010: 8).

Türkiye İstatistik Kurumu (2009)'e göre, ülkemizde 65 yaş üstündeki nüfus oranı $\%$ 7'dir. Ancak, 2023 yılında bu oranın \% 10 olacağ 1 öngörülmektedir. Gelecek yıllarda Türkiye'deki nüfus artış hızı devam etmekle birlikte nüfusun içindeki yaşlı birey sayısı, genç nüfusa göre daha fazla olacağ mektedir. Dünya Sağlık Örgütü, Türkiye'nin gelecek 25 yılda nüfusunun \% 30 artarken, 65 yaş üstü nüfustaki artış oranının \% 120 olacağını öngörmektedir (WHO, 2002).

Mevcut veriler, demografik değişimin, ülkelerin ekonomilerini çok ciddi bir şekilde zorlayarak kamu harcamaları, büyüme ve iş yapısı üzerinde önemli bir daralma meydana getireceğini göstermektedir (Kuneva ve Diğ, 2010). Çünkü, nüfus içindeki yaşlı oranının artırması, beraberinde kronik hastalıkların artışını gündeme getirmektedir. Kronik hastalıklar; yaşlıların günlük yaşam aktivitelerini olumsuz etkilemekte, yaşam kalitelerini düşürmekte ve bir başkasına bakıma muhtaçlık düzeyini artırmaktadır. Güngör ve diğ. (2009) yapmış olduğu bir araştırma sonucuna göre, 65 yaş üstündeki bireylerin yaklaş1k \% 80'inde en az bir, \% 50 'sinde ise en az iki kronik hastalığ 1 olduğu ifade edilmektedir.

Öte yandan, yaşlanmayla birlikte artan sağlık ve sosyal bakım sorunlarının şiddetli ve ürkütücü boyutta olacağ 1 varsayılmaktadır (Bremner ve diğ., 2010). Çünkü; özürlülük, kronik hastalık ve bakıma muhtaç yaşlıların bakımı uzun süreli olabilmektedir. Uzun süreli bakım, 6 aydan daha fazla süren, tıbbi hizmetler yanında sosyal bakım hizmetlerin verilmesini kapsayan hizmetlerdir (Oğlak, 2008:19).

Artan yaşlı nüfusun uzun süreli bakım gereksinimi, hiç şüphesiz sağlık ve sosyal bakım hizmetleri sunumu ile harcamalar üzerinde önemli bir baskı unsuru oluştura-

* Yaşlı bağımlılık oranı, 65 yaş ve üzerindeki nüfusun çalışma yaşı olarak kabul edilen 20-64 yaş arasındaki nüfusa oranını ifade etmektedir. 
caktır. Bu nedenle, yaşlanmanın sosyal güvenlik sistemi ve ülke ekonomilerinin yap1sında ciddi bir zorlama yapacağı, sağlık ve sosyal bakım harcamalarının akılalmaz boyutlara ulaşacağı öngörülmektedir. Çünkü, yaşlanmaya bağlı ortaya çıkan kronik hastalıklar ve bakım maliyetleri, genç nüfusa oranla daha fazla olmaktadir (Australian Government Department of Health and Ageing, 2006; Centre for Policy on Ageing, 2011). Sözgelimi, ABD'nin 1970 yılında sosyal güvenlik harcamaları GSMH'nın \% 4'ünü oluştururken 2010 yılında \% 8.4'e ulaşmış, 2030 yılında ise \% 15'e ulaşacağı tahmin edilmektedir (Population Reference Bureau, 2010). Öte yandan, AB'de, sağlik hizmetleri-emekli maaşları, uzun süreli bakım hizmetleri gibi yaşlılıkla ilişkili kamu harcamalarının 2060 yılında GSMH içindeki payını ortalama \% 4-4.5 artıracağ edilmektedir (European Commission Directorate-General for Economic and Financial Affairs, 2009).

Bilindiği üzere, Uluslararası Çalışma Örgütü (ILO)'nun 102 nolu sözleşmesi, temel sosyal güvenlik hakları olarak; klasik anlamda sağlık, hastalık, işsizlik, yaşlılık, meslek hastalığının yanı sıra "bakıma muhtaç olmay1" da "sosyal risk" olarak tanımlanmiştır (MISSOC, 2009). Başta Almanya olmak üzere birçok $A B$ ülkesi, Japonya gibi ülkeler, bakıma muhtaç bireylerinin bakım sorumluluğunun yalnızca ailenin ve toplumun değil devletin de olduğunu kabul ederek sosyal güvenlik sistemi içinde bakım gereksinimini karşılayacak yeni düzenlemelere/çözümlere yer vermeye başlamışlardır. Sözü edilen çözümlerin bireyin ve ailesinin gereksinimi karşılayacak olması yanında, maliyeti düşük bakım modelleri olması da büyük önem kazanmaktadır. Genel olarak bakıldığında, sözü edilen modellerin yap1landırılmasında şu değerler esas alınmaktadır (Kuneva ve diğ., 2010).

- Yaşlının aktif yaşlanma ile toplumdan uzaklaşmadan yaşayabileceği bir model olmalı,

- Mali kısıtlılıkları göz önünde bulundu- rarak daha iyi bakım, daha iyi sağlık verileri ve daha fazla yaşam kalitesi ile memnuniyeti sağlayacak bakım çözümleri yaratılmalı,

- Bakıma muhtaç yaşlılara sağlanan tüm formal ve informal bakımın yerine getirilmesinde holistik bakım modelleri uygulanmalıdır.

Öte yandan, yaşlanma; toplumsal dişlanma, depresyon, yalnızlık duygusunun artması ve sosyal entegrasyonun azalması gibi yaşam kalitesini doğrudan etkileyen yeni sorunları da beraberinde getirmektedir (Kuneva ve diğ., 2010). Bu bağlamda, yeni yaşlılık bakım hizmetleri modelinin, maliyet etkin bir çözüm olması yanı sıra bireylerin yalnızlık duygusunu en aza indirecek, topluma katılımını artıracak, fonksiyonel kapasitesini devam ettirecek, başkalarına olan bağımlılığı en aza indirecek ve aynı zamanda yaşam kalitesini yükseltecek bütüncül (holistik) yeni altyapılar ve yeni çözümlerin bulunmasına ihtiyacı ortaya çıkarmıştır.

\section{ALTERNATIF ÇÖZÜMLER: TOPLUMA DAYALI BAKIM HIZMET ÇÖZÜMLERİ}

Artan sağlık harcamaları baskısı, bakım hizmetlerinde uzman ve yarı uzman bakım işgücü (hemşire, sosyal çalışmacı, psikolog, fizyoterapist, diyetisyen, meşguliyet ve konuşma terapisti, sosyal bakım elemanı vb) yetersizliği ile birlikte yaşlıların sağlık ve sosyal bakım hizmetlerini evlerinde ve yaşadıkları ortamda alma tercihlerinin ön plana çıkması; ülkelerin yaşlı bakım politikalarını, topluma dayalı bakım hizmetlerinin desteklenmesi yönünde değiştirmelerine neden olmuştur (The Community-Based Aged Care Workforce, 2006; Australian Government Department of Health and Ageing, 2006)

Kurumsal bakım modelinin alternatifi olarak gelişen topluma dayalı bakım hizmetleri, yaşlının onurunu ve saygınlığını koruyan, yaşam kalitesini yükselten, toplumsal dışlanmayı önleyen ve ihtiyacı olan hizmet- 
leri yaşadığı ortamda almasını sağlayan model olarak ön plana çıkmaya başlamıştır (Oğlak, 2008; van Bilsen ve diğ; 2008).

Kurumsal bakım hizmetleri; hastane, huzurevi ve bakım merkezlerini kapsarken, topluma dayalı bakım hizmetleri, bakım hizmetlerinin bireyin evinde ya da yaşadığ çevrede verilmesine odaklanmaktadır. Genel olarak, AB ülkeleri, ABD, İsrail, Avustralya, Kanada, Japonya gibi birçok ülkenin kurumsal bakım hizmetleri yerine bireyin gereksinimine göre değişebilen topluma dayalı bakım hizmetlerine (evde bakım, gündüz bakım, gece bakım, evlere yemek dağıtım, destekleyici teknolojilerin (tele tıp, tele bakım, tele evde bakım vb.) yönelmişlerdir. Amaç, bireylerin olabildiği kadar evinde, ailesi ve yakınlarılla birlikte kalmasını sağlamak ve kurumsal bakımın artan maliyetlerini azaltmak ve bireyin memnuniyeti ile yaşam kalitesini yükseltmektir (MISSOC, 2009).

Türkiye'de de son y1llarda toplumsal yapıda meydana gelen hızlı değişmeler, yaşlıların geleneksel aile ve akrabalık ilişkilerinin dişında, devlet desteğine ve profesyonel hizmetlere olan gereksinimini artırmıştır. Bilindiği gibi, huzurevleri, "Kurumsal Bakım Modeli" olarak, yaşamlarını tek başlarına sürdürmeleri zorlaşan yaşlının barınma, dinlenme ve temel ihtiyaçlarını karşılayan bir bakım modeli olarak ülkemizde oldukça yaygındır. Diğer yandan ise, yaşlılar; huzurevlerini, sevdiklerinden ve yaşadığı çevrelerinden uzaklaştırdığı, bireyleri yalnızlaştırdığ 1 ve zorunlu kalmadıkça tercih etmek istemedikleri bir yer olarak görmektedirler (Danış, 2001; DPT, 2007; Bölükbaș ve Arslan, 2003). TÜİK, Aile Yapısı Araştırması (2006) sonuçları, yaşlıların \% 55'inin çocuklarıyla kalmak, yalnızca \% 9'unun, huzurevine gitmek istediklerini ortaya çıkarmıştır (TÜİK, 2006; 25). Geçmişteki anlayışın tersine, bugün artık kendi bulunduğu ortamda, ancak yaşamı kolaylaştıran ve yaşlıya göre düzenlenmiş koşullar altında hayatını sürdürmeye yönelik hizmetlerin daha iyi bir çözüm olduğu değerlendiril- mektedir (DPT, 2007; 51). DPT tarafindan hazırlanan (2007) “Türkiye'de Yaşlıların Durumu ve Ulusal Eylem Planı"nda özellikle yaşlıların yaşadığ 1 ortamda kalmalarını ve sağlık ve sosyal bakım hizmetlerine yaşadığı ortamlarda ulaşabilmeleri yönünde öneriler geliştirilmiştir. Buna göre;

a.Yaşlıların ihtiyaçlarının göz önünde bulundurulması ve yaşamin bütün dönemlerinde onurlu yaşama hakkına sayg1 duyulması,

b. Yaşlıların kültürel, ekonomik, politik ve sosyal yaşam ile yaşam boyu öğrenmeye katılımlarının sağlanması ve sürdürülmesi amacıyla teşvik edilmesi için olanaklar yaratılması, programlar hazırlanması ve destek olunması, yaşlıların, evleri ve huzurevi dışındaki sosyal ortamlara erişimlerinin sağlanması

c. Temel sağlık hizmetleri, uzun süreli bakım, gündüzlü bakım ve evde bakım ve sosyal hizmetler ile diğer toplum hizmetlerinin koordinasyonunun sağlanması ve iyileştirilmesi,

d. Yaşlıların beden ve ruh sağlığ sından kendi yaşam alanlarının korunması için evde bakım ve tedavi hizmetlerinin geliştirilmesi, bununla ilgili politikaların oluşturulması ve kurumlar arası işbirliğinin sağlanması

Türkiye'de, son on yıldır değişen eğilime paralel olarak, sosyal bakım anlayışı doğrultusunda kurum bakımı modeline dayalı uygulamalardan, topluma dayalı bakım anlayışına dayalı mevzuat ve uygulamalara (Yaşlı Hizmet Merkezlerinde Sunulacak Gündüzlü Bakım ile Evde Bakım Hizmetleri Hakkında Yönetmelik, SHÇEK: 07.08.2008. Sayı: 26960; Bakıma Muhtaç Özürlülere Yönelik Resmî Kurum ve Kuruluşlar Bakım Merkezleri Yönetmeliği. SHÇEK. 30.07.2006. Sayı: 26244; Bakıma Muhtaç Özürlülere Yönelik Özel Bakım Merkezleri Yönetmeliği. SHÇEK. 30.07.2006. Sayı: 26244; Evde Bakım Hizmetleri Sunumu Hakkında Yönetmelik. Sağlık Bakanlığı. R.G. Tarihi:10.03.2005. 
Say1:25751) yer verildiği görülmekle birlikte sosyal güvenlik sistemi içinde tam anlamıyla yer almamış olması ve ihtiyacı olan bireylere ulaşamaması önemli bir eksiklik olarak değerlendirilmektedir. Öte yandan, birey odaklı, holistik ve entegre bakım hizmetlerinin verildiğini söylemek henüz mümkün görülmemektedir.

\section{EVDE BAKIM HIZMETLERI}

Evde bakım hizmetleri; bireyin yaşadığ 1 yerde ve gereksinimlerine göre koruyucu bakım, tıbbi tedavi ve rehabilitasyon ile sosyal bakım hizmetlerini kapsamaktadır (Hilman, 2002). Başka bir ifadeyle, evde bakım hizmetleri bireyin sağlığını ilgilendiren; sağlığın korumasına ve sürdürülmesine yönelik, hastaların hastanede daha kisa süre yatmasını sağlamak ya da uzun süreli bak1min verildiği huzurevi veya benzer bakım kuruluşlarının yerini alan bakım hizmetlerinin evinde ya da yaşadığ 1 yerde verilmesidir (Chappell, 2000).

Evde bakım programları; bireylerin evinde veya onun yaşadığı çevrede ihtiyaçları olan sağlık ve sosyal bakım hizmetleri sunmak ve koordine etmek amaciyla bireye özel yapılandırılan bir program olarak tanimlanmaktadır. Hastane bakıminin tamamlayıcısı olmasının yanısıra, bakımın sürekliliğini sağlama veya uzun süreli bakım gerektiğinde de yerine getirilebilen evde bakım, üç ana farklı amaçla uygulanabilen bir hizmet modelidir (Office of Health and Information Highway Canada,1998: 5).

1.Akut ve kısa süreli bakım hizmetlerine destek olmak amaciyla verilen evde bakım,

2.Uzun süreli bakım gereksinimi için evde bakım,

3.Tıbbi, hemşirelik ve rehabilitasyon hizmetlerinin bileşiminden oluşan evde sağlık bakımı.

Halamandaris (1985), evde bakım hizmetlerinin üstünlüklerine ilişkin birçok nedenin olduğunu, bunların arasında en dikkat çekici olanlarının; bireye üst düzeyde özgürlük sağlaması, bireyin gereksinimine odaklı ve yaşam kalitesini yükseltmesi olduğunu vurgulamaktadır.

Tüm gelişmiş ülkelerde evde bakım hizmeti 1980'lerden sonra büyüyen bir endüstri olmaya başlamıştır. Evde bakım hizmetleri hemşireler (\% 60), sosyal hizmet uzmanları, fiziksel, meşguliyet ve konuşma terapistleri, diyet uzmanları, hekimler ve sosyal bakım elemanları tarafından sağlanmaktadır. Bu hizmetler büyük çoğunlukla belediyeler, kamu kuruluşları, kar amaçlı, kar amaçsız evde bakım kuruluşları ve gönüllüler tarafından verilmekle birlikte son zamanlarda hastaneler de evde bakım pazarı içinde yer almaya başlamışlardır (Office of Health and Information Highway Canada, 1998).

Evde bakım hizmetleri, ülkemiz için yeni bir sağlık ve sosyal bakım hizmet modeli olarak kabul edilmiş olmakla birlikte, özellikle sosyal güvenlik sistemi içinde yer almamış olmasından dolayı bu hizmetler arzu edilen düzeyde yaygınlaşmamıştır.

\section{GÜNDÜZ BAKIM MERKEZİ HIZMETLERİ (YAŞLI KREŞi)}

Gündüz Bakım Merkezi, huzurevinin artan maliyetlerine ve yaşlının topluma dayalı bakım hizmetleri taleplerinin yükselmesine ciddi bir alternatif olarak devletin ve ailelerin daha fazla tercih ettikleri bir bakım modeli olarak 1970 yillarından buyana gelişmiş ülkelerde uygulanan bir bakım modelidir (Lucas ve diğg, 2002). Huzurevi ve evde bakım arasında ara çözüm alternatifi olarak gelișen gündüz bakım merkezi (GBM); kurumsal bakım merkezlerine gidişi geciktiren, güvenli ve sağlıklı bir ortam yanında sosyal katılımı sağlayan bir bakım modeli olmasının yanı sıra, maliyeti düşük bir hizmet modelidir (Bilotta ve diğ., 2010; JDCESHEL, 2010; Shannon ve di $\breve{g} ., 1998$ ).

GBM, 65 ve üstündeki bireylere, tıpkı okul öncesi çocukların gittikleri kreş anlayışı ile hizmet etmekte ve haftanın beş günü 0817 saatleri arasında hizmet sunmaktadırlar. 
$\mathrm{Bu}$ merkezler; fiziksel ve duygusal olarak kontrol altında tutulması, gözlenmesi gereken yaşlının sosyal aktivite, fiziksel egzersizlerin, aynı zamanda arkadaşlık ilişkilerinin sağlandığ 1 yerlerdir (DPT, 2007; Walker, 2006; Tate ve Brennan, 1998). Özellikle kendisine bakamayan, evinde yalnız yaşayan veya bakıma muhtaç yaşlılara ev d1şında güvenli bir ortamda hizmet sunma ilkesine dayanmaktadır. GBM'nin bir diğer önemli katkısı ise; yaşlısına bakan aile bireyinin bakım yükünü azaltmasıdır (NADSA, 2009; van Bilsen ve diğ., 2008). Özellikle kronik hastalığı olan (bunama, inme, parkinson vb.) yaşlıların aile bireylerinin bakım yükünün azaltılmasına önemli bir katkı sağlamaktadır (Shannon ve diğg., 1998)

Yaşlılar için en büyük sorun toplumsal soyutlanma, zihinsel ve fiziksel sağllk, yalnızlık ve depresyondur. Ama asıl korkutucu olanın ise tüm bunların sıklıkla bir arada görülmesidir. Yaşlı hizmetlerine yönelik sunulacak hizmetlerin amacı; yaşlıların kendilerini güvende hissedecekleri, aktif ve daha fazla kendi yașadıkları ortamda yașayabilecekleri bir çevrenin (ortamin) yaratılmasidir. (Independent Age Supporting Older People at Home, 2010; 6). Yapilan birçok çalışma; bireyin topluma katılımı ve depresyon arasında çok yakın bir ilişki olduğu, herhangi bir sosyal aktivite içinde yer alan yaşlilarda depresyon riskinin daha düşük düzeyde olduğu görülmüştür (Bilotta ve diğ., 2010). GBM, yaşlının güvenliğini sağlama, güvenli bir çevre oluşturma, toplumsal entegrasyon, kendi yaşıtlarıyla arkadaşlık geliştirilmesi ve aktivitelere katılım gibi çeşitli fırsatlar sağlamaktadır (Baumgarten ve diğ., 2002). Aynı zamanda, sosyal katılım ile yaşam kalitesi arasında doğrusal bir bağlantı olduğu, sosyal destek sistemlerinin sağlanması ile yaşam kalitesinin yükseldiğine ilişkin kanıtlar ortaya konulmuştur (Bilotta ve diğ., 2010; Molzahn ve diğ., 2009; Stern ve Caro, 2004). GBM'ne kayıtlı yaşl1larda anksiyete, güvensizlik, depresyon, yalnızlık gibi psikososyal sorunların azaldığına ilişkin uluslararası düzeyde çok sayıda çalışma bulunmaktadır (Bilotta ve diğ., 2010;
Mavrovouniotis ve diğ., 2010; Molzahn ve di ğg., 2009; Gitlin ve diğ., 2006)

Ülkemizde yaşlıların büyük çoğunluğu ailesi ile yaşamaktadır. Yalnız ya da ailesi ile birlikte yaşayan bakıma muhtaç yaşlılar, aile bireyi için uzun vadede sorun olmakta, çoğu kez ne yapacaklarını bilememektedirler ve hatta aile ilişkileri de bozulmaktadır. Böyle olunca da, yaşlı, evinde sadece temel ihtiyaçları karşılanan, hiçbir sosyal etkinlik ve iletişim ortamında yer almayan, sürekli kendini dinleyerek daha fazla hastalık şikayetinde bulunan (daha fazla hastaneye gitme, daha fazla ilaç tüketimi) bir birey olarak kabul edilmektedir. Gündüz saatleri içinde hem mevcut yetilerinin korunması ve başkasına bağımlı olmadan yaşayabilecek becerilerin kazandırılması, hem de sosyal aktiviteler içinde yer almasını sağlayacak bir merkezin olması, yaşlının yaşam kalitesinin yükselmesi kadar, ailesinin yaşlıya bakışının değişmesine de yardımcı olacaktır (Oğlak, 2010).

Tüm gelişmiş ülkelerde yaklaşık 30 yıldır uygulanmakta ve hem yaşlının, hem bak1minı üstlenen ailesinin, hem de devletin yarar sağladığı evde bakım ile huzurevi arasında çok önemli bir ara çözüm modeli olan GBM, 2008'de bu konuya ilişkin yasal düzenleme (SHCEK, 2008) yürürlüğe girmiş olmasına karşın Türkiye'de henüz yaygın bir şekilde tanınmamakta ve uygulanmamaktadir. Oysa, 16 milyon nüfuslu Yunanistan'da yaklaşık 700, İsrail'de 180, ABD'de 5000 GBM olmasına (JDC-ESHEL, 2010; NADSA, 2009) ve $A B$ ülkelerinde çok yaygın bir şekilde uygulanmasına rağmen, ülkemizde henüz yaygınlaşmamış olması oldukça düşündürücüdür.

\section{MEALS-ON-WHEELS (YEMEK DAĞITIMI) HIZMETLERI}

Yeterli ve dengeli beslenme, yaşlılarda sağlık durumu ve yaşam kalitesinin korunması açısından hayati bir öneme sahiptir. Ancak, beslenme sorunları, yaşlılarda çok sık rastlanılan bir sağlık sorunudur (Elia ve Smith, 2009:3) ve bireyin sağlık durumunun 
bozulmasına veya bir başka hastalığın ortaya çıkmasına zemin hazırlayabilmesi gibi daha tehlikeli sonuçlara yol açabilmektedir. Yetersiz ve yanlış beslenme; kronik hastalığa sahip, gelir düzeyi düşük, sosyal yönden dışlanmış, mental ve fiziksel olarak bakıma muhtaç yaşlılar için büyük bir risk oluşturmaktadır (Elia ve Smith, 2009:3; NHS Tayside, 2002). İngiltere'de yaşlıların \% 25'inde kötü beslenme sorunu olduğu ve özellikle evinde yaşayan yaşlıların \% 93'nde kötü beslenme bulgularına rastlandığ belirtilmektedir (Graham ve diğ., 2010; Elia ve Smith, 2009).

Bu anlamda son yıllarda birçok gelişmiş ülkede örneklerine rastlanılan ve çoğu kez devlet, yerel yönetimler, yardım kuruluşları ve gönüllüler tarafından finanse edilebilen meals-on-wheels (yemek dağıtımı) hizmetleri; yaşlılara ücretsiz veya düşük maliyetli beslenme menüleri sağlayabilmektedir. $\mathrm{Bu}$ sayede düzenli bir ögüüle yeterli ve dengeli beslenme sağlanarak başka hastalık ve istenmeyen durumların ortaya çıkışı önlenmiş olmaktadır (Timonen ve O'Dwyer, 2010: 5).

Evinde yaşayan ve destek hizmetlere gereksinim duyan yaşlılara sağlanan yemek dağıtımı hizmetlerinin bir diğer önemli yararı ise; sağlık harcamalarının azaltılmasına önemli katkı sağlamasıdır (Graham ve diğ., 2010). Örneğin, İngiltere'de hastalıkla ilişkili kötü beslenmeye bağlı kamu harcamalarının sağlık ekonomisi üzerindeki etkisinin büyük olduğuna dikkate çekilmiş ve Ulusal Sağlık Sistemi (NHS) içinde; herkes için yüksek kaliteli bakım stratejisi geliştirilerek beslenme ve tedavinin önemine yönelik düzenlemelere yer verilmiştir (DH, 2009; Darzi, 2008). Yapılan sistemli çalışmalar, yemek dağıtımının sağlanması ile 65 yaş üstündeki yaşlıların kötü beslenmeye bağlı oluşan tedavi giderlerinde ciddi düzeyde tasarruf sağlandiğ 1 ve 2008'de 7.3 milyona indiği, 2012 y1lında da, 4.2 milyon Sterline ineceği belirtilmektedir (Graham ve diğ., 2010).

Diğer yandan, yemek dağıtımı hizmeti; sıcak öğün sağlamasının yanı sıra yaşlı bireylerle kurulan iletişim yoluyla yalnızlıkla- rının giderilmesinde önemli bir boşluğu doldurmaktadır (Sorophire Council, 2010: 12). Çünkü, yalnızlık, bireyleri depresyona itmekte ve çoğu kez beslenme ve yeme içmeye olan ilgiyi azaltmaktadır. Özellikle yalnız ve/veya dul yaşlılar sağlıklı beslenme hakkında fazla deneyimleri olmaması nedeniyle nasıl alınacağ1 ve pişirileceği konusunda zorlanmakta, çoğu kez dengeli ve yeterli beslenmeden yoksun gidalarla beslenmektedirler (Timonen ve O'Dwyer, 2010: $5)$.

Birçok çalışma sonuçları, yemek dağıtımı hizmetinden yararlanan yaşlılar ve özürlülerin, kendilerini daha güvende ve daha az yalnız hissettiklerini ve sosyal ilişkilerinin artmasına da büyük katkı sağladığını göstermektedir (Timonen ve O'Dwyer, 2010: 7; Sorophire Council, 2010; Graham ve diğ., 2010). Ayrıca, yemek dağıtımı yapan görevliler de yaşlı bireylerin genel sağlık durumu hakkında bilgi sahibi olduklarından olumsuz bir gelişmeyi daha erken fark ederek koruyucu sağlık hizmetine önemli bir fayda sağlamaktadırlar (Graham ve diğ., 2010). Avusturalya kaynaklı bir araştırmada da, yemek dağıtımı hizmeti alanlarda yalnızlık düzeyi daha düşük bulunmuş, hemen hemen yarısı da, yemek dağıtımı yapan kişiyle kurmuş oldukları iletişimden dolayı mutlu olduklarını belirtmişlerdir. (Timonen ve O'Dwyer, 2010:7).

\section{YAŞLI BAKIMDA TEKNOLOJININ KULLA- NIMI: TELE BAKIM-TELE TIP ÇÖZÜMLERI}

Bakım işgücünün artan yaşlı bakım taleplerini karşılamada yetersiz olması, güvenli ev ortamı sağlama ve acil durumlarda zaman kaybının önlenmesi, farklı bakım stratejilerinin geliştirilmesi zorunluluğunu ortaya çıkarmıştır (The Community-Based Aged Care Workforce, 2006). Evde destekleyici teknolojilerin kullanılması; artan yaşlı bakım hizmet talepleri gibi sorunlar karşısinda anahtar bir çözüm olarak görülmekte ve çeşitli teknolojilerin kullanımını hızlandıran faktörlerden birini oluşturmaktadır $(\mathrm{Ku}-$ neva ve diğ., 2010:10; The 
Community-Based Aged Care Workforce, 2006). Destekleyici teknolojiler genel olarak tele tıp, tele sağlık bakım, tele evde bakım vb. çeșitli tanımlarla ifade edilmektedir. Tele tıp, tele sağlık bakım; hastaların, yaşlıların, özürlülerin evinde ya da bakım kurumlarında, gerekli tıbbi teşhis, tedavi, danışmanlık ve/veya sağlığı korumak amacıyla iki yollu bilgi ve verilerin transfer edildiği bir elektronik iletişim ağının kullanılması olarak tanımlanmaktadır. Tele evde bakım ise genel anlamda; evde bakım hizmeti veren kuruluşların telekominikasyon teknolojisinden yararlanarak bakıma yönelik bilgi, eğitim veya hizmetleri; telefon, bilgisayar, interaktif TV, işitsel, görsel cihazlar veya her birinin farklı kombinasyonlarını kullanmak suretiyle hizmeti bakıma muhtaç bireylere ulaştırması olarak tanımlanmaktadır. (Koch, 2005: 14) Kullanılan teknolojiler; iletişim, hareketlilik kabiliyeti, elle komutlandırma, çevreye uyum sağlama ve bilişsel olmak üzere çeşitli gruplara göre sinıflandırılmaktadır (Kuneva ve diğ., 2010).

Tele bakım ve tele tıp, yaşlı bireylerin başkalarına olan bağımlılıklarının azaltılması ve bireyin gereksinimine uygun bakım ve destek hizmetlerin verilmesinde yenilikçi fırsatlar sağlamaktadır. Tele bakım ve tele tıp; yaşlıların evinde yalnız yaşayabilmesinin devamlılığının sağlanabilmesinde, hizmetlere ulaşabilmesinde ve almasında çok önemli bir role sahiptir (Sorophire Council, 2010: 12).

Sözkonusu teknolojinin kullanımı; yaşl1ların özerkliğinin korunması ve onurlu bir yaşam sürdürmesine de olanak sağlamaktadır. Ayrıca, vücudun temel bazı hareket işlevlerinin ve fonksiyonlarınin yerine getirilmesine destek sağlamanın yanı sıra, fiziksel ve sosyal çevrenin düzenlenmesine yönelik ürünler de olabilmektedir. Özellikle son yıllarda gelişen teknolojiye bağlı olarak, bakım hizmetlerinde robot kullanımına ağırlık verilmektedir. Tüm gelişmiş ülkelerde evde sağlık bakım teknoloji kullanımı dikkate değer ölçüde artmaktadır. Yaşlı ve bakıma muhtaç bireylerin evleri gereksinimine yardımcı olabilecek özel alarm, özel geliştirilmiş kolye, acil uyarı butonları, cep telefonları, banyo rayları, düşmeyi anında merkeze ileten uyarı sistemleri ve yangın-su basmalarında uyarı butonları gibi diğer yardımcı araç sistemleri ile donatılmaktadır (Office of Health and Information Highway Canada, 1998). Destekleyici teknolojinin kullanımı; ayrıca, teşhis, bakım, koruma, güvenlik ve danışmanlık hizmetlerinin uzaktan sağlanmasına da olanak sağlamaktadır.

Destekleyici teknolojiden yararlanma; yaşlının başkalarına olan bağımlılı̆̆ını azaltan, yaşam kalitesini yükselten ve ev ve birey güvenliğini artıran aynı zamanda topluma katılmasını daha fazla kolaylaştıran temel bir öğe olarak görülmektedir. Ayrıca, yaşlının fonksiyonel kapasitesini artırdı ğ gibi bir başkasına duyulan yardımları potansiyel olarak en aza indirdiğinden formal ve informal bakım gereksinimini de azaltmaktadir. (Office of Health and Information Highway Canada, 1998: 42). ABD'de evde bakım hizmeti alan bakıma muhtaç yaşl1larda destekleyici teknolojinin kullanılmasinin, personel giderlerinin azaltılmasina önemi ölçüde katkı sağladığı görülmüştür (Mann ve diğ., 1999). Öte yandan, evde bakım hizmetlerini zenginleştirme ve genişletme kapasitesini artırmakta (Office of Health and Information Highway Canada, 1998: 8) ve çeşitli uygulamalarla maliyetetkin çözümler sunmaktadırlar. Şöyle ki:

- Acil servislere gereksiz gelişlerin azaltılmas1

- Hekim muayenehanelerine gidişin azaltılması (planlanmamış)

- Erken müdahale yapılması veya hastaneye yeniden yatışın önlenmesi

- Hastalara başlangıç belirtilerin öğretilmesi ve ne yapacakları hakkında bilgilendirilmeleri nedeniyle akut olumsuz koşulların ortaya çıkışının önlenmesi

- Yaşlıların bakım hizmetlerine kolaylıkla erişebilmeleri

- Hayati bulgularının olası değişimi kar- 
şısında erken müdahale olanağı sağlamas1

- Erken teşhis ve tedavide önemli bir bileşen olan 24 saat süreyle hayati bilgi akışına dair bilgilerin elde edilmesi sağlanmış olmaktadır.

Tele tıp, tele bakım veya tele evde bakım; yaşlının ve sosyal bakım elemanının memnuniyetinin artmasında, bakım hizmetlerinin daha düşük maliyette ve daha etkin sunumunun sağlanmasında çok önemli rol oynamaktadır. Bu nedenle Avrupa ve diğer ülkelerde geniş çapta yeni pazar firsatları yaratılmaktadır. Çeşitli projeler çerçevesinde, evinde ve/veya bakım kurumlarında yaşayan yaşlıların bakım hizmetlerinde kullanıminin yaygınlaşması bu alanda yeni ve hayatı kolaylaştırıcı çözümlerin her geçen gün artırılarak kullanıcıların hizmetine sunulması hedeflenmektedir. Özellikle AB'de Ambient Assisted Living (AAL) gibi çeşitli projeler geliştirerek bu teknolojinin toplumda bireylerin/kurumların kullanımı ve yaygınlaştırılması sağlanmaktadır (Kuneva ve diğ., 2010). Diğer yandan, hayatı kolaylaştırıcı çözümler sunması, bireylere özgürlük alanı sağlaması ve maliyetleri azaltması yönünde de etkili sonuçlar ortaya çıkarması; ülke ekonomilerine ve topluma muazzam bir fırsat sağlayacak olan daha geniş kapsamlı sosyal politika düzenlemelerinin yapılmasını da hızlandırmaktadır (Kuneva ve diğ., 2010).

\section{SONUÇ}

Bakıma muhtaç yaşlilar, genel anlamda yalnız ve toplumdan soyut, birçok tıbbi ve sosyal hizmetlere ulaşımda sıkıntıları olan önemli bir grubu oluşturmaktadır. Bakıma muhtaçlık bir sosyal risk olarak tanımlanmakta ve yaşlı bakımında yalnızca ailelerin ve toplumun değil, aynı zamanda devletin de önemli bir sorumluluğu olduğu kabul edilmektedir. Devlet bu sorumluluğunu yerine getirirken yaşlı bireylerin ve ailelerinin bakım tercihlerini dikkate almak zorundadır. Günümüzde $A B, A B D$, Japonya, İsrail gibi birçok gelişmiş ülkeler; demografik, ekonomik, toplumsal ve kültürel yapıda ortaya çıkan değişiklikler ve talepler karşısında sosyal politikalarını ağırlıklı olarak kurumsal bakım hizmetlerinden, topluma dayalı bakım hizmetleri yönünde değiştirmelerine neden olmuştur. Sözü edilen bu uygulamalar; yaşlıyı sosyal yaşamdan, günlük alışkanlıklarından, arkadaş, komşu ve akrabalarından ayırmayan, yaşam kalitesini yükselten, fonksiyonel kapasitesini koruyan ve geliştiren, güvenli bir ev ortamında sağlık ve sosyal bakım hizmetlerine ulaşabilmelerini ve boş zamanlarını en iyi ve verimli biçimde geçirebilmelerini sağlayan bakım hizmet modellerinin hayata geçirilmesini sağlamıştır.

Türkiye, henüz genç nüfusa sahip olmasına karşın, yaşlı nüfus oranının giderek artacağ1 öngörüsü gerçeğinden hareketle yaşlıların bakım sorunlarına yönelik topluma dayalı bakım modelleri konusunda somut adımların atılması ve yaşlılık ve getireceği bakım sorunları karşısında bugünden düzenlemelerin yapılması gerektiği ortadadır. Ülkemizde de topluma dayalı bakım anlayışına doğru eğilimin görüldüğü ve evde bakım ve gündüz bakım hizmetlerine yönelik yasal düzenlemelerin yapılmış olması sevindirici olmakla birlikte, finansal yönünün sosyal güvenlik sisteminde tam anlamıla yer almamış olması, toplumun genelinde bu hizmetlerin alınmasında büyük engel oluşturmaktadır. Bu anlamda, ülkenin tüm vatandaşlarını kapsayan bakım sigortası uygulamasının hayata geçirilmesi, yaşlilara verilen önemin göstergesi olmanın ötesinde sağlıklı yaşlanma politikaları için de bir başlangıç olacaktır. Bu açıdan bakıldığında politikacılar, kanun yapanlar, bilim insanları, hizmeti sağlayanlar, sigorta kuruluşları ve sivil toplum kuruluşları bu alandaki rollerini/sorumluluklarını göz önünde bulundurarak çeşitli projelerle bakım modellerinin uygulanması, yapılan uygulamaların sürdürülebilirliğine destek sağlanması ve toplumsal farkındalık oluşturarak yaşlılara yönelik topluma dayalı bakım hizmetlerinin yaygınlaştırılması yönünde çaba harcamalıdırlar. 


\section{Kaynakça}

Australian Government Department of Health and Ageing (2006). The Community-Based Aged Care Workforce. http: / / www.health.gov.au/internet/main/publishing.nsf

Baumgarten M, Lebel P, Laprise H, Leclerc C, Quinn C (2002). "Adult Day Care for the Frail Elderly: Outcomes, Satisfaction, and Cost". Journal of Aging and Health, Vol. 14 No. 2, May, 237-259

Bilotta CB, Spreafico LS, Vergani C (2010). "Day care centre attendance and quality of life in depressed older adults living in the community", Eur J Ageing, 7:2935

Bölükbaş N, Arslan H (2003). “Huzurevinde Kalan Yaşliların Psikososyal Yönlerinin incelenmesi". Düşünen Adam, 16(4): 235-239

Bremner J, Frost A, Haub C, Mather M, Ringheim K, Zuehlke E (2010). “World Population Highlights:Key Findings From Population Reference Bureau's 2010 World Population Data Sheet". Population Bulletin. Vol. 65, No. 2. July. www.prb.org

Centre for Policy on Ageing (2011). "How can local authorities with less money support better outcomes for older people?". January. Joseph Rowntree Foundation

Chappell NL (2000). "Maintaining the Integrity of Home Care", Healthcare Papers, Volume 1, No:4, Fall 2000, Erişim; 18.09.2003,http:/ / www.longwoods.co $\mathrm{m} / \mathrm{hp} /$ fallo0/9.html.

Danış ZM (2001). "Yoksulluk ve Yalnızlık". Hacettepe Üniversitesi Geriatrik Bilimler Araştırma ve Uygulama Merkezi (GEBAM). http://www.gebam.hacettepe.edu.tr/sosyal_boyut/yaslilik_yoksuluk_yanlizlik.pdf
Darzi L (2008). High Quality Care For All, NHS Next Stage Review Final Report Summary. Department of Health (DH)

Department of Health (DH) (2009). Nutrition Action Plan Delivery Board End of Year Progress Report, August. http://www.dh.gov.uk/prod_consum_dh/groups/dh_digitalassets/@d h/@en/@ps/documents/digitalasset/dh_113150.pdf

Devlet Planlama Teşkilatı (2007). Türkiye'de Yaşlıların Durumu ve Yaşlanma Ulusal Eylem Planı, Sosyal Sektörler ve Koordinasyon Genel Müdürlüğü, Yayın No DPT: 2741

Elia M, Smith RM (2009). Improving Nutritional Care And Treatment-Perspectives and Recommendations from Population Groups, Patients and Carers . BAPEN Publishing, UK

European Commission Directorate-General for Economic and Financial Affairs (2009). The 2009 Ageing Report: Economic and Budgetary Projections for the EU-27 Member States (2008-2060) European Commission (DG ECFIN) and the Economic Policy Committee (AWG). European Economy 2/2009. ISBN 97892-79-11363-9.

Gitlin LN, Reever K, Dennis MP, Mathieu E, Hauck WW (2006). "Enhancing Quality of Life of Families Who Use Adult Day Services: Short- and Long-Term Effects of the Adult Day Services Plus Program", The Gerontologist, Vol. 46, No. 5, $630-63$

Graham R, Rhonda S, Derek J (2010). Later Life Conference 2010; Shaping the Future of Care Together. 28 January. Apetito. http:/ / www.publicserviceevents. co.uk/wshop_pdf/1110-apetito.pdf 
Güngör G, Güler N, Kocataş S, Akgül N (2009). "Yaşlıların Sağlık Bakım Gereksinimleri". Cumhuriyet Tip Dergisi; 31: 367-373

Halamandaris V (1985). "Twenty Reasons for Home Care", Caring Magazine, Vol.IV. No:10

Hilman L(2002). “Maximum Impact-Looking to the Future", Canadian Home Care Association 12. Annual Conference, November 22-23-Vancouver-B.C, pp.2-3

Independent Age Supporting older people at Home (2010). "Older people, technology and community: the potential of technology to help older people renew or develop social contacts and to actively engage in their communities". Independent Age Supporting older people at Home and Calouste Gulbenkian Foundation UK

Koch S (2005). "ICT-based Home Healthcare - Research State of the Art". VINNOVA Report VR 2005:11. VINNOVA - Swedish Agency for Innovation Systems. ISBN: 91-85084-40-9

Kuneva M, Dózsa C, Mann E, Miles I, Parent AS, Vasconcelos D (2010). Unlocking innovation in ageing well. Independent Panel Report Interim Evaluation of the Ambient Assisted Living Joint Programme, December

Lucas JA, Rosato NS, Lee JA, Howell-White S (2002). "Adult Day Health Services: A Review of the Literature", The Institute for Health, Health Care Policy, and Aging Research, Rutgers Center for State Health Policy, August
Mann WC, Ottenbacher KJ, Fraas L, Tomita M, Granger CV (1999). "Effectiveness of Assistive Technology and Environmental Interventions in Maintaining Independence and Reducing Home Care Costs for the Frail Elderly. A Randomized Controlled Trial", Archives Family Medicine. 8:210-217

Mavrovouniotis HF, Argiriadou AE, Papaioannou SC (2010). "Greek traditional dances and quality of old people's Life", Journal of Bodywork \& Movement Therapies Vol:14, 3. pp.209-218, doi:10.1016/j.jbmt.2008.11.005

Molzahn EA, Gallagher E, McNulty V (2009). "Quality of Life Associated with Adult Day Centers", Journal of Gerontological Nursing, Vol. 35, No. 8

Mutual Information System on Social Protection in the EU Member States, The EAA and Switzerland (MISSOC) Secretariat (2009). Long-Term Care. Missoc Analysis, European Commission DG Employment, Social Affairs \& Equal Opportunities. Contract No: VC/2008/0967

NADSA (2009). "Adult Day Services: Overview and Facts", Erişim 14.12.2009, http://www.nadsa.org/

NHS Tayside (2002). “Nutrition Guidelines for Older People. Good practice guidelines for carers of older people in Tayside". NHS Board, Directorate of Public Health. http:/ / www.thpc.scot.nhs.uk

Office of Health and Information Highway Canada (1998). "Tele-Homecare: An Overview Background Paper for Discussion. Office of Health and the Information Highway Policy and Consultation Branch Health Canada", May. http://www.hc-sc.gc.ca/hcssss / pubs / ehealth-esante / 1998tele/index-eng.php 
Oğlak S (2010). Gündüz Bakım Merkezlerinde İstidam Edilecek Sosyal Bakım Aktivite Elemanı Yetiştirme Projesi'nin Faaliyet ve Sonuçları, İzmir Valiliği İl Sosyal Yardımlaşma ve Dayanışma Vakfı Yayınları, Okullar Yayınevi, İzmir. Mayıs.

Oğlak S (2008). Evde Bakım Hizmetleri ve Bakım Sigortası (Ülke Örnekleri), İskenderun Belediyesi Kültür Yayınları, No:6, ISBN: 978-9944-5417-1-8, 359 sayfa, 2. Basım. Nisan

Population Reference Bureau (2010). World Population Data Sheet.www.prb.org.p.6

Ringheim K (2010). “Gender, Employment, and Dependency. (2010) World Population Highlights:Key Findings From Population Reference Bureau's 2010 World" . Population Data Sheet. Population Bulletin. Vol. 65, No. 2. p.8. July. www.prb.org.

Shannon JE, Zarit SH, Berg S, Johansson L (1998). "Adult day care for dementia: A comparison of programs in Sweden and the United States", Journal of CrossCultural Gerontology 13: 99-108.

SHCEK (2008). "Yaşlı Hizmet Merkezlerinde Sunulacak Gündüzlü Bakım ile Evde Bakım Hizmetleri Hakkında Yönetmelik", $\quad$ 07.08.2008. Say1: 26960. www.shcek.gov.tr

Sorophire Council (2010). Report of the Meals on Wheels and Promoting Independence (Preventative Services) Task and Finish Group. Sorophire Council Community Services Scrutiny Committee.August. p.12. http://www.shropshire.gov.uk

T.C.Sağlık Bakanlığı (2005). “Evde Bakım Hizmetleri Sunumu Hakkında Yönetmelik".www.saglik.gov.tr.
Stern AL, Caro FG (2004). "Consumer Perspectives on Quality in Adult Day Care", Gerontology Institute McCormack Graduate School of Policy Studies University of Massachusetts, Boston, MA, February

Tate L, Brennan MC (1998). “Adult Day Care: A Pratical Guidebook and Manual", The Haworth Pres, Inc. ISBN 086656-711-9

The Association for the Planning and Development of Services for the Aged in Israel (JDC-ESHEL) (2010). Adult Day Care, http://en.eshelnet.org.il/category/Day_Care_Centers, Erişim: 10.December 2010

The Community-Based Aged Care Workforce (2006). "Characteristics of Community-Based Aged Care Workforce (Including Volunteers) In Selected Countries; Technology and The Community-Based Aged Care Workforce: Possible Workforce Impacts" - Draft, March.

Timonen V, O'Dwyer C (2010). "It is nice to see someone coming in: exploring the social objectives of Meals-on-Wheels". Canadian Journal on Aging,29(3):399410.

TÜİK (2006). “Aile Yapısı Araştırması”. T.C Başbakanlık Türkiye İstatistik Kurumu, T.C Başbakanlık Aile ve Sosyal Araştırmalar Genel Müdürlüğü (ASAGEM). Türkiye İstatistik Kurumu Matbaası. Ankara.

TÜİK (2009) Türkiye Nüfus Bilgisi, www.tuik.gov.tr

van Bilsen PMA, Hamers JPH, Groot W, Spreeuwenberg C (2008). "The use of community-based social services by elderly people at risk of institutionalization: An evaluation", Health Policy 87; 285-295 
Walker MG (2006). How to Start an Elderly Adult Day Care Center. Step Out on Faith Publishing ISBN: 0-9672052-5-5

World Health Organization (2002). Lessons for Long-Term Care Policy, $\mathrm{WHO} / \mathrm{NMH} / \mathrm{CCL} / 02.1$. 
